\title{
EVALUATION MODEL OF MNES' KNOWLEDGE FLOW MANAGEMENT
}

\author{
Fengming Tao, Weidong Meng \\ College of Economics and Business Administration, Chongqing University, Chongqing, \\ 400030.China,Email:taofengming@cqu.edu.cn
}

\begin{abstract}
With the brief introduction of knowledge and knowledge flow, this paper pointed out that knowledge flow management is essential for MNEs in such a global and information economy. Three elements affect the knowledge flow in MNEs and the index system is constructed based on these three elements. Evaluation model which is constructed with AHP and fuzzy set is built for MNEs to assess their knowledge flow management.
\end{abstract}

Key words: evaluation model; knowledge flow management; MNEs

\section{INTRODUCTION}

As Porter (1986: 17) observed, "we know more about the problems of becoming a multinational than about strategies for managing an established multinational", in today's global economy, if MNEs (multinational enterprises) want to be competitive as a whole, they must achieve a balance among the following four characteristics in knowledge management: the organizational ability to learn; the capacity to rapidly respond to the environmental changes; the ability to coordinate and integrate knowledge present in different locations; and the capacity to minimize costs in relation to competitors. Each one of the above requirements is essential but very difficult to complete. It is necessary to develop a knowledge strategy centrally managed, which leads the creation and application of strategic knowledge.

Please use the following format when citing this chapter:

Tao, Fengming, Meng, Weidong, 2006, in International Federation for Information Processing (IFIP), Volume 207, Knowledge Enterprise: Intelligent Strategies In Product Design, Manufacturing, and Management, eds. K. Wang, Kovacs G., Wozny M., Fang M., (Boston: Springer), pp. 71-78. 
Globally distributed networks of subsidiaries constitute a potentially important source of competitive advantage for MNEs. By accessing the knowledge residing in these networks, MNEs can both exploit existing repositories of knowledge and combine these sources of knowledge to explore new issues. This argument, highlighting the potential importance of knowledge as a strategic resource, has brought the transfer of competence across units into focus as a central challenge for MNEs management. It has also triggered a considerable amount of research on factors influencing interunit knowledge transfer patterns within the differentiated MNEs. However, with certain notable exceptions (e.g., Gupta and Govindarajan, 2000), few efforts have been made to examine the influence of organizational mechanisms on knowledge flow within MNEs (Foss and Pedersen, 2002). In particular, there is a lack of research on the strategies that MNE headquarters may use to ensure that the competence of subsidiaries is transferred across different units. The question addressed in this paper is therefore: How do different factors impact on flows of knowledge within MNEs and how can we weight them and evaluate them?

\section{KNOWLEDGE FLOWS IN MNES}

\subsection{Knowledge}

Knowledge flows are understood as the aggregate volume of know-how and information transmitted per unit of time. Such a concept means to capture the overall amount of know-how and information transmitted between parent and subsidiaries and between subsidiaries themselves in all kinds of ways.

And there are two kinds of knowledge: explicit knowledge and tacit knowledge. Explicit knowledge is knowledge articulating and codifying in handbooks, computer programs, databases and training tools, among other elements, and this knowledge is transmissible. Tacit knowledge is personal, context specific and difficult to regularize. It includes cognitive element, which is mental patterns such as beliefs, points of views etc. that help individuals to perceive and define their environment. Organizations are considered to be a depositary of several types of knowledge (explicit and tacit) existing in different levels (individual, group, organizational and interorganizational). 


\subsection{Knowledge flows}

According to Mudambi (2002), this paper views knowledge flows through the source-target perspective. Each knowledge flow occurs between a source and a target along a channel. Knowledge flows are therefore taken to be node-specific and dyadic. Principally, four knowledge flows will be concerned.

1 Flows from the parent (and other MNE units) to the subsidiary: These flows from the parent to the subsidiary are the traditional flow, where the subsidiary exploits a home-base knowledge advantage.

2 Flows from subsidiary to parent (and other MNE units): High levels of these flows enable MNE headquarters to exploit local competencies and act as a knowledge intermediary or knowledge integrator.

3 Flows from host country to subsidiary: These flows consist of the subsidiary's learning, local competence exploitation, and local resource utilization.

4 Flows from subsidiary to host country: These flows are part of "spillovers". In the literature, spillovers have often been used to refer to flows both into and out of the firm. However, as our analysis is firm-centric rather than location- centric, here, spillovers only mean outflows from the subsidiary.

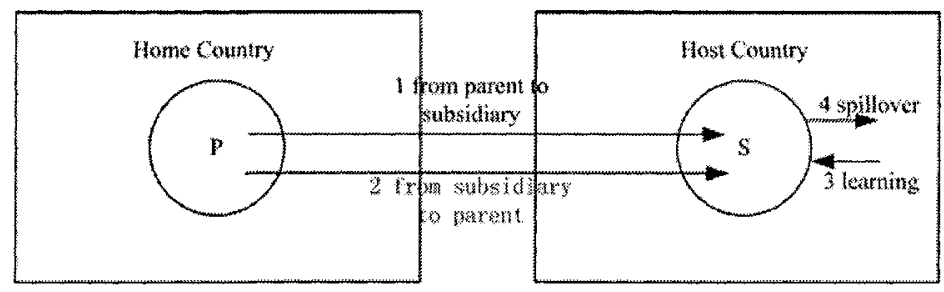

Figure 1 Principal Knowledge Flows in MNEs

\section{IMPORTANCE OF KNOWLEDGE FLOW MANAGEMENT}

Knowledge management is an organizational process that covers the creation or acquisition of knowledge, its combination, deployment, renovation, storage and transference of both intra- and inter- organizationally. Through adequate human resource management system architectures, the enterprise can support its knowledge management strategy. In this sense, 
especially the creation or acquisition of knowledge as well as its transfer are managed within the HR function.

The existence of a strong co-operative and collaborative culture is an important prerequisite for knowledge transfer between parent company and its subsidiaries. Without appropriate mechanisms to encourage co-operation, structured or technological interventions to facilitate knowledge transfer may not work. Establishing a collaborative and co-operative climate in an organization will improve knowledge transfer. Several works on international management and specifically on international human resource management suggest that an important aspect for MNEs is the degree in which management systems applied in the country of origin can answered back in a foreign country.

With all the discussion above, we can see that knowledge flow management is so important for MNEs that the directors of MNEs need to improve the efficiency of their knowledge flow management. Therefore, we should first of all build a scientific system to evaluate the knowledge flow management in MNE so that we can evaluate it and improve it. The following part is the brief introduction of the comprehensive evaluation model with AHP (Analysis Hierarchy Process) and fuzzy set.

\section{INDEX SYSTEM OF THE EVALUATION MODEL}

\subsection{Hierarchies of Index}

Since knowledge flow means knowledge flows between two or more units along a channel, we can evaluate knowledge flow management in MNEs through these three indexes: knowledge; units that send and receive knowledge; and the environment that knowledge flows happen. And the three indexes constitute the first hierarchy. That is, the first hierarchy is $B_{i, i}$ $=1,2,3$; and $B_{i}$ is made up of the second hierarchies $C_{i j} . B i=\left\{C_{i j}\right\}$. The following is the hierarchies of the index system.

\subsection{Knowledge}

Knowledge evolves through interactions between new knowledge and prior, related knowledge. Therefore, knowledge flows are kind of path dependence, and we ought to focus on knowledge stock and flow at the same time. Hereby, $B_{l}$ knowledge is composed of the following second hierarchies: size of MNE $\left(C_{11}\right)$, history of MNE $\left(C_{12}\right)$, relative economic level of MNE $\left(C_{13}\right)$, and average annual investment in $\mathrm{R} \& \mathrm{D}$ in 5 years $\left(C_{14}\right)$ 




Figure 2 Hierarchies of the index system

\subsection{Sender and receiver of knowledge}

In nature, knowledge flow in enterprises is a process of mutual learning among individuals, groups and subsidiaries, hence, the learning abilities and motivation can somewhat decide the efficiency of learning. Hereby, $B_{2}$ sender and receiver is composed of the following second hierarchies: learning motivation of employee $\left(B_{21}\right)$, learning ability of employee $\left(B_{22}\right)$, ability to use the network $\left(B_{23}\right)$, learning motivation of enterprise $(B 24)$, and learning ability of enterprise (B25).In nature, knowledge flow in enterprises is a process of mutual learning among individuals, groups and subsidiaries, hence, the learning abilities and motivation can somewhat decide the efficiency of learning.

\subsection{Environment}

Knowledge flow management is totally different from one enterprise to another, and of course different from one country to another. Therefore, MNEs can have an influence in the transferability of its knowledge through the design of the organization structure, business strategies and human resource management system with enough consideration of cultural difference. In this way, MNEs can create a better environment to have knowledge flow more efficiently. Hereby, $B_{3}$ environment is composed of the following second hierarchies: strategy construction for knowledge flows 
$\left(B_{3 l}\right)$, organization structure of $\mathrm{MNE}\left(B_{32}\right)$, motivation system $\left(B_{33}\right)$, training and learning system $\left(B_{34}\right)$.

\section{EVALUATION MODEL WITH AHP AND FUZZY SET}

\subsection{Weight of index}

Based on the index system above, we can fix the weight of indexes with AHP (Analysis Hierarchy Process). According to Seaty, we compare the indexes pairwise and quantify them on basis of stated scales and then construct the judge matrix $M$. This process should be implemented by experts. The Characteristic root of the judge matrix $M$ is the weight coefficient of the indexes in the same hierarchy.

The weight of the second hierarchy $W i$ should be firstly found out. Take the four indexes belonged to Environment that knowledge flows happen $\left(B_{3}\right)$ as the example, with several experts' suggestion, we can get the weight scores of the four indexes and then get the judge matrix.

Table 1 Example of weight scores of the second hierarchies

\begin{tabular}{|l|c|c|c|c|}
\hline \multicolumn{1}{|c|}{$\mathrm{i}$} & $\begin{array}{c}\text { strategy } \\
\text { construction }\end{array}$ & $\begin{array}{c}\text { organization } \\
\text { structure }\end{array}$ & $\begin{array}{c}\text { motivation } \\
\text { system }\end{array}$ & $\begin{array}{c}\text { training and } \\
\text { learning system }\end{array}$ \\
\hline strategy construction & 1 & $1 / 3$ & $1 / 5$ & $1 / 4$ \\
\hline organization structure & 3 & 1 & 4 & 4 \\
\hline motivation system & 5 & $1 / 4$ & 1 & $1 / 5$ \\
\hline training \& learning system & 4 & $1 / 4$ & 5 & 1 \\
\hline
\end{tabular}

Therefore, the judge matrix is:

$$
\mathbf{M}=\left[\begin{array}{cccc}
1 & 1 / 3 & 1 / 5 & 1 / 4 \\
3 & 1 & 4 & 4 \\
5 & 1 / 4 & 1 & 1 / 5 \\
4 & 1 / 4 & 5 & 1
\end{array}\right]
$$

\subsection{Fuzzy comprehensive evaluations}

For each index, there are five scales for experts to evaluate, that is, 
$\mathrm{V}=\left\{\mathrm{v}_{1}, \mathrm{v}_{2}, \mathrm{v}_{3}\right\}=\{$ very good, good, medium, bad, very bad $\}$.

Then, based on experts' evaluation, we can get $r_{i j k}$ which is the degree of membership. The implication of $r_{i j k}$ is to what degree experts think index $C i j$ can be judged as level. And $R i$ can be expressed as:

$$
R_{i}=\left[\begin{array}{cccc}
r_{i 1} & r_{i 12} & \cdots & r_{i 1} \\
r_{i 21} & r_{i 22} & \cdots & r_{i 2} \\
\cdots & \cdots & \cdots & \cdots \\
r_{i m 1} & r_{i n 1} & \cdots & r_{i m m}
\end{array}\right]
$$

$n$ is the number of lines in the matrix and its implication is the number of indexes. And $m$ is the number of rows in the matrix and its implication is the number of levels in $V$.

Finally, we can have the multi-level fuzzy comprehensive evaluation. According to the weight coefficient of the indexes $W i$ and the judge matrix $R i$, we can calculate the fuzzy comprehensive evaluation sets of the second hierarchy: $G i=W i \cdot R i=\left(g_{i 1}, g_{i 2}, g_{i 3}\right)$. In this expression, the implication of $\left.g_{i k}(i=1,2,3,4,(5)) ; k=1,2,3,4,5\right)$ is the degree of membership of $B i$ to each level $v_{k}(k=1,2,3,45)$ when assess the factors $C i j$ belong to $B i$ in the second hierarchy.

With the result calculated from the above, we can have the fuzzy comprehensive evaluation of the first hierarchy based on the judge matrix of the second hierarchy. And the formula is as the following:

$$
R=\left[\begin{array}{c}
G_{1} \\
G_{2} \\
G_{3} \\
G_{4} \\
G_{3}
\end{array}\right]=\left[\begin{array}{ll}
W_{1} \cdot R_{1} \\
W_{2} \cdot R_{2} \\
W_{3} \cdot R_{3} \\
W_{4} \cdot R_{4} \\
W_{5} \cdot R_{5}
\end{array}\right]
$$

\section{CONCLUSIONS}

MNEs face important challenges. The enterprise must lean how to exploit its specific resources either acquired in the country of origin or in foreign markets; and they should know that the source of sustained competitive advantage takes place in the variety of skills and the diversity of knowledge, not in these resources homogeneity. 
In MNEs, individual pieces of knowledge are embedded in an interconnected network of other pieces that provide an ecological context for changes in knowledge. Changes in some parts of the knowledge structure tend to induce changes in other, related or similar parts. Therefore, this paper builds a systematic evaluation model to test capacity of knowledge innovation and efficiency of knowledge transference in MNEs.

Through this model which is constructed with AHP and fuzzy set, MNEs can find out whether there exist any problems in knowledge flow management and dig out what lead to these problems. This evaluation model is comparatively scientific, but there are still some limits need to improve. Most of the indexes are subjective and might be totally different from one person to another. Therefore, a team of good and experience experts is the guarantee of the effect of this model.

\section{REFERENCES}

Foss, N.J. and Pedersen, T. 2002, Transferring knowledge in MNCs: the role of sources of subsidiary knowledge and organizational context, Journal of International Management 8(1): $1-19$.

Frost, T. 2001, The geographic sources of foreign subsidiaries' innovations, Strategic Management Journal 22: 101-123.

Ghoshal, S.,\&Nohria, N. 1989, Internal differentiation within multinational corporations. Strategic Management Journal. 10, 323-337.

Ghoshal, S., Khorine, H. and Szulanski, G. 1994, Interunit communication in multinational corporations, Management Science, 40(1): 96-110.

Gupta, A.K., \& Govindarajan, V. 1991. Knowledge flows and the structure of control within multinational corporations. Academy of Management Review, in press.

Mudambi, R. 2002, Knowledge management in multinational firms, Journal of International Management 8(1): 1-9.

Nohria, N. and Ghoshal, S. 1994, Differentiated fit and shared values: alternatives for managing headquarters-subsidiary relations, Strategic Management Journal 15(6): 491502.

Nonaka, I. and Takeuchi, H. 1995, The Knowledge-Creating Company, Oxford University Press: Oxford.

Osterloh, M. and Frey, B.S. 2000, Motivation, knowledge transfer and organizational forms, Organization Science 11(5): 538-550.

Porter, M.E. 1986, Competition in global industries: a conceptual framework, competition in Global Industries, Harvard Business School Press, Boston, MA: 15-20.

Torbiorn, I. 1985, The Structure of Managerial Roles in Cross-Cultural Settings, International Studies of Management and Organization 15(1): 52--74.

Van de Ven, A.H. and Polley, D. 1992, Learning While Innovating, Organization Science 3(1); 92-116.

White, R.E. and Poynter, T.A. 1985, The strategies of foreign subsidiaries, International Studies of Management and Organization 14(4): 91-106. 